DOI: http://dx.doi.org/10.22198/rys.2018.73.a930

Artículos

\title{
Minería y territorio: acercamientos teóricos al campo de la historia ambiental a través de un estudio de caso
}

\author{
Mining and territory: theoretical approaches \\ to the field of environmental history through \\ a case study
}

\author{
Francesco Panico* \\ orcid.org/0000-0001-8883-9385
}

Resumen: el objetivo del artículo es esbozar un marco epistemológico que sitúe al campo de la historia ambiental en el quehacer actual de las ciencias sociales y las humanidades. La metodología utilizada se define aquí como "hitos metabólicos”, porque está inspirada en el enfoque del metabolismo social. Los resultados apuntan a que, en el estudio de la historia ambiental, el objeto historiográfico concreto desempeña un papel fundamental en la definición del contexto epistémico de ese campo híbrido de la historiografía y, más en general, de los análisis sociales y ambientales.

Palabras clave: historia ambiental; historiografía; metabolismo social; minería; Mazapil.

* Universidad Veracruzana, Facultad de Sociología. $3^{a}$ Privada de Ma. Esther Zuno de Echeverría \#28, colonia Zapata, C. P. 91093, Xalapa, Veracruz, México. Correo electrónico: panchop75@hotmail.com 
Abstract: this article aims to outline an epistemological framework for placing the field of environmental history in the context of the current endeavor of social sciences and humanities. The methodology used is defined here as "metabolic landmarks" because it is inspired by the approach of social metabolism. The results suggest that, in the study of environmental history, the specific historiographical object plays an essential role in defining the epistemic context of that hybrid field of historiography and, more generally, of social and environmental analyses.

Key words: environmental history; historiography; social metabolism; mining; Mazapil.

Recibido el 24 de mayo de 2017. Aceptado el 29 de septiembre de 2017.

\section{¿Qué historia ambiental?}

El interés de la historiografía moderna por estudiar la relación hombre-naturaleza es una novedad, surgida en el seno de una conciencia política renovada, a partir de la década de 1960. Situar el inicio de esta aventura del conocimiento no es tarea grata para los especialistas, puesto que el problema del origen acarrea otra cuestión más fundamental, que atañe al corazón mismo de la complejidad de los vínculos históricos y de la dificultad de establecer conexiones significativas entre los hechos. Entonces, aquí no se retomará esta prolija tarea, el estudio se concentrará en tratar de brindar un marco teórico de referencia, para que la historia ambiental adquiera una dimensión concreta. ${ }^{1}$

El primer asunto que se impone es el del sentido de la relación; ¿qué se está relacionando: sociedad y naturaleza; hombre y naturaleza; cultura y naturaleza; sociedad y medio ambiente? La primera histo-

1 Para profundizar en los temas inherentes a la historia ambiental y campos afines, se puede consultar a Worster (2008); Latour (2007); Escobar (2006); Descola y Pálsson (2001); Sieferle (1993) y Meadows et al. (1972). 
riografía ambiental, como respuesta a la clásica (que, a principios del siglo XX, pasó por alto el humus teórico de inspiración bergsoniana, que caracterizó más tarde el planteamiento braudeliano acerca de la duración) resolvió centrar su discusión en la dimensión ecosistémica de esa relación (Saba 2000). No obstante, los geógrafos y los antropólogos, y no los historiadores, se nutrieron intensamente de ese debate (Worster 2008, 24). Desde sus inicios hasta hoy, la historia ambiental ha ampliado mucho sus alcances, hasta convertirse en un ámbito de discusión del que ha surgido una variedad rica en propuestas teóricas y metodológicas (Acevedo y Martínez Alier 2005; García 2006; Leff 2005). Éstas han recuperado, en los últimos 30 años, el fundamento social del quehacer historiográfico (como sugería la escuela de los Annales) abriéndolo a un debate más atento y crítico de la evolución histórica (Burke 1992). La novedad, con respecto al planteamiento de los "annalistas" (Braudel en particular), fue la decisión metodológica de no separar la historia geográfica de la social y política, pues el objeto de análisis de la nueva historiografía no era el tiempo sino el proceso histórico. Ésta debía ser capaz de hablar de temporalidades diferentes (para recuperar la idea braudeliana de la duración), que se entrelazan a lo largo de una trayectoria hecha de continuidades y de cambios. Estas temporalidades son las que al final permiten abandonar la jaula teórica que se había construido alrededor del dualismo hombre-naturaleza.

Sobre esta línea, en la última década empezó a trabajar el metabolismo social (Toledo y González de Molina 2007), una perspectiva teórica novedosa, impulsada desde España y América Latina, cuya mirada se detiene en el análisis del fundamento material de la relación compleja entre fenómenos humanos y naturales. Dicho de forma sencilla, el metabolismo social introduce al multifacético objeto historiográfico en las posturas sistémicas de la ciencia ecológica. Sin duda, la obra clásica del economista Georgescu-Roegen (1996) constituye un antecedente importante de esa nueva historiografía ambiental (Martínez Alier 1995; Toledo 2013). Los flujos energéticos, es decir, la capacidad de un sistema de absorber y devolver en otra forma la energía utilizada durante el proceso de trabajo (en sentido termodinámico) representan el núcleo duro de su planteamiento, como también la idea de que el ser humano siempre ha representado un extraordinario fenómeno movilizador de energía, a través de una re- 
lación social, productiva y cultural con los recursos disponibles en su entorno directo. ${ }^{2}$ Es necesario precisar que el metabolismo social, en el marco de esta reflexión muy breve, no constituye la metodología que se aplicará para demostrar la vigencia de las dinámicas de cambio y permanencia en una región, a través de la modificación de los flujos de energía, sino que representa una idea fecunda, que se utilizará como referente para la argumentación, a fin de promover pesquisas ulteriores. En razón de ello, no se analizará la base material sobre la cual ocurrieron estos cambios en el contexto del estudio, sino que se sugerirá una hipótesis fundamentada en datos históricos, que apunta a la sucesión de procesos distintos, cuyas rupturas aquí se llamarán "hitos metabólicos".

Sobre esta base es posible esbozar un marco teórico particular para la historia ambiental tomando como referencia las idiosincrasias propias de un objeto de estudio, la minería, y de un territorio peculiar, el antiguo real minero de Mazapil (véase Figura 1), en el actual estado de Zacatecas, México. ${ }^{3}$

Figura 1. Real minero de Mazapil, en Zacatecas

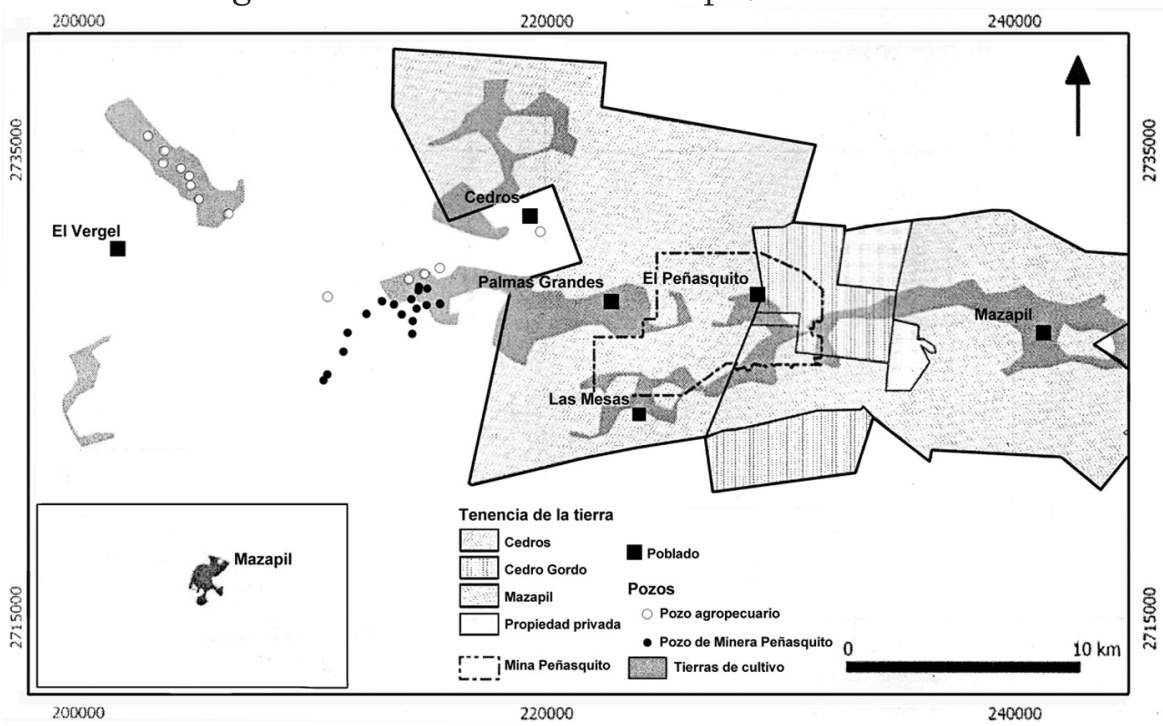

Fuente: Boni et al. (2014).

2 En la actualidad, el planeta entero representa el "entorno directo" en el que se enmarcan las opciones civilizatorias, bajo el impulso de un modo de vida que se caracteriza por mucho dispendio de energía (Prigogine 2004).

3 La información histórica relativa a Mazapil es muy escasa; para corroborar la mencionada en textos historiográficos más amplios, tanto espacial como temporalmente, se hace referencia 


\section{La centralidad del objeto historiográfico}

La importancia del objeto historiográfico no radica en brindar una simple plataforma material a una teoría preconcebida, sino que acompaña la edificación de ésta. Es importante recordar que la historia ambiental, a diferencia de otros ámbitos académicos más tradicionales, no es una disciplina formal, sino un campo de conocimiento abierto. Por esta razón, en ella el objeto de estudio adquiere un peso específico mayor con respecto al de otras áreas de investigación. En este sentido, la historia ambiental, por las circunstancias en las que se gestó y desarrolló posteriormente, es un contexto ideal para ensayar las potencialidades del objeto en la construcción activa de un campo de conocimiento. Entonces, las preguntas medulares serán las siguientes: ¿cómo la historia de la minería puede contribuir a un mejor entendimiento de la historia ambiental?; ¿de qué manera un estudio monográfico sobre temas mineros puede ser la base empírica de este entendimiento? La tarea aquí es explorar el sentido de estos interrogantes.

La importancia de la minería para la historia ambiental: el caso de Mazapil

Los hitos metabólicos

Las divisiones históricas planteadas en este párrafo encuentran respaldo en la modificación de las estructuras socioambientales, que constituyen la base de la relación productiva y reproductiva de una sociedad con su entorno. En Mazapil, los hitos metabólicos medulares, en correspondencia con ciertos periodos históricos (que no son exclusivos de la región en cuestión), son: a) el establecimiento del real de minas y la integración social de la actividad minera durante la época colonial; b) el advenimiento de la minera industrial nueva, dentro de la 
división internacional del trabajo, a inicios del siglo XX y c) la llegada de la minería corporativa, en la primera década del nuevo milenio.

Estas rupturas metabólicas coinciden con tres periodos históricos específicos, que no se adscriben tout court, a las dinámicas internas del valle, como se puede observar fácilmente, sino que son el resultado de factores externos a éste. ${ }^{4}$ Las fluctuaciones energéticas de gran magnitud que interesan a este territorio no se pueden separar del escenario más amplio de la evolución civilizatoria, pues son provocadas, en primera instancia, por dinámicas que se inician fuera del contexto regional de estudio.

Cabe aclarar que la división propuesta no corresponde a una visión última y definitiva del proceso histórico local, pues hay otras maneras de interpretarlo y proponerlo. Este trabajo sólo pretende ser un intento de explorar las potencialidades del quehacer historiográficoambiental, a través de un objeto específico. En función de ello, es necesario revisar más a fondo los tres hitos propuestos y ser consecuente, de ese modo, con la intención de que este artículo constituya la base conceptual para estudios ulteriores, por tanto, no plasma una metodología específica.

\section{El valle de Mazapil: una larga historia agrominera}

Mazapil, como muchos de los enclaves que trazan la geografía humana del norte mexicano a lo largo del periodo colonial, nació como sitio de defensa en el marco de una sociedad de conquista. Dentro de este contexto nuevo, los grupos nómadas fueron desplazados violentamente. El conflicto entre su territorialidad y la importada de España resultó muy desestabilizante para los equilibrios anteriores, debido a que la minería necesitaba cantidades formidables de energía. La mi-

4 En el primer caso, el establecimiento de reales de minas fue una práctica común en toda la América hispánica; en el segundo, la transición del campo a la industria en México y América Latina comenzó a partir de la segunda mitad del siglo XIX, coyuntura que provocó un aumento rápido de la energía movilizada; en el tercero, el paso de una economía de fábrica a una financiera y de divisas, caracterizó a los últimos 50 años de la historia mundial, junto a formas nuevas de explotación de commodities, que en la actualidad no se extraen con facilidad (como el oro y la plata), son los factores que determinan el salto energético del último hito señalado. 
nería ampliaba, de una forma jamás vista, el alcance de los procesos metabólicos ${ }^{5}$ del valle, y los encausaba hacia el ámbito geoeconómico mayor del intercambio interoceánico, vinculado al sistema financiero europeo y al comercio mediterráneo (Braudel 2001). En el norte minero, la organización productiva, edificada en función de la explotación de los metales preciosos, creó un tipo peculiar de sociedad agrominera, en la que el vínculo con la tierra se mantuvo como una característica esencial de las relaciones socioambientales. La minería, a pesar de instaurarse como la actividad principal con vocación exportadora, nunca desplazó a la agricultura ni a la ganadería. Éstas se impusieron como las empresas económicas, que acompañaron al proceso interno de creación de una organización social fundada sobre bases corporativas, cobijada por tradiciones y prácticas novohispanas. Al final del periodo virreinal, primero con las reformas borbónicas y luego con la consumación de la independencia, la propiedad y el uso de la tierra en el valle de Mazapil (como también en gran parte del norte), no sufrieron cambios significativos. La economía agrominera siguió siendo la base productiva, se conservaron las vastas extensiones de las haciendas y rancherías, el peonaje y el trabajo en las minas definían las características de las relaciones laborales y, en muchos casos, se compenetraban como las actividades principales de subsistencia de los campesinos sin tierra (Boni 2010; Panico y Garibay 2010). Las reformas liberales de mediados del siglo XIX y el modernismo porfirista no trasformaron de manera radical la vida del campo. Durante la etapa final del porfiriato, la minería pasó a constituir el centro de un sistema metabólico mucho más extenso y gravoso, que el que había sostenido a la sociedad virreinal y a la primera parte de la independencia. A lo largo de este periodo, la modernización de la minería en Zacatecas, pese a que nunca representó la palanca de un desarrollo industrial pleno, produjo una alteración del equilibrio agrominero anterior, que sólo la revolución, a través de la institución de la propiedad social (el ejido), pudo contrarrestar de alguna forma. La Reforma Agraria generó un proceso lento de redistribución de la tierra en favor de las comunidades campesinas, cuyos integrantes de-

5 En general, un proceso metabólico es el flujo de las trasformaciones energéticas, cuyo incremento o decremento es visible fácilmente sobre el aspecto del territorio. 
pendían de los recursos naturales de las grandes haciendas, según las modalidades de trabajo y de aprovechamiento. La industrialización incipiente, que había puesto en peligro la continuidad del régimen agrominero, fue atenuada por los nuevos arreglos territoriales resultado del proceso revolucionario. Una vez más, pese a su abrupto crecimiento estructural y a la necesidad de contar con mayores flujos de energía, la minería no determinó una descomposición del régimen agrominero. Los campesinos dejaron de ser peones y salieron de la estructura corporativa de la hacienda, para incorporarse al nuevo patrón ejidal y a la recién estrenada organización paternalista del Estado mexicano posrevolucionario; siguieron siendo campesinos, pero también mineros. Esta forma de reproducción socioeconómica local contrarrestó la proletarización masiva del campesinado, y en paralelo palió la escalada metabólica del sistema agrominero regional. En el marco de las reformas neoliberales de las últimas tres décadas, la llegada de la minera canadiense Peñasquito al valle de Mazapil, en 2006, ha sido el detonador de las nuevas dinámicas territoriales. La minería a cielo abierto es muy diferente con respecto a la del pasado, puesto que necesita una cantidad de energía sin precedentes. La corporación controla todos los recursos naturales y humanos del valle, pues ninguna otra actividad socioeconómica sería viable frente al monstruo energético que representa la minería moderna. De eso se desprende que el metabolismo del valle haya sufrido un agigantamiento, en términos de uso y trasformación de la energía disponible. Los recursos locales no son suficientes para alimentar esta voraz maquinaria. La tierra, el agua y, en general, el territorio, enfrentan una situación de estrés permanente, que está llevando a una desaparición forzada de las relaciones socioproductivas y ambientales anteriores.

\section{Vieja y nueva economía minera en Mazapil}

La estructura agrominera durante el periodo virreinal

Durante el siglo XVIII, el distrito de Mazapil estaba ocupado por seis grandes haciendas agroganaderas (Bonanza, Cedros, San Isidro, La Gruñidora, Sierra Hermosa y Pozo Blanco) y 28 ranchos con una población aproximada de 5500 personas. Las posesiones de Bonan- 
za, propiedad del marqués de Aguayo (ubicadas al norte del actual poblado de Mazapil), y las de Cedros (al este del valle) del minero Juan Lucas de Lazaga, contaban con una estructura urbana pequeña y los servicios de un cura (Langue 1999, 295). Esto significa que las grandes posesiones de los hacendados-mineros eran, de facto, sociedades organizadas alrededor de un proyecto político-territorial que unía la modernidad exportadora con el patrimonialismo local. Se calcula que en 1778, sólo en Mazapil, había casi medio millón de ovinos, y los caballos y las mulas llegaban a 10 mil. Las haciendas de Cedros y Bonanza se extendían sobre un territorio que rebasaba las 100 mil hectáreas; y se podían mantener sólo en función de la explotación minera, ya que sus producciones diversificadas permitían el funcionamiento de dicha maquinaria, pero también eran la base para la continuidad de las redes clientelares establecidas por los hacendados. Muchos de estos terratenientes participaban directamente, o a través de sus socios y allegados, en la administración de las ciudades y de los reales zacatecanos, y desde allí construyeron un sistema de concesiones (asientos), para controlar la burocracia y el mercado locales. Era difícil que el poder central del Virreinato llegara a estas tierras alejadas. Ni siquiera las reformas borbónicas, a finales del siglo XVIII, pudieron desmantelar estas prácticas, pues los mineros controlaban, a través del Tribunal de Minería, ubicado en la Ciudad de México, los aparatos productivos y políticos de las zonas auríferas y argentíferas de la Colonia. Los capitanes-mineros habían instituido verdaderos reinos en sus mayorazgos, en donde ellos eran los únicos dueños reconocidos.

Cedros y Bonanza operaban según un sistema mixto y complementario, basado en la agroganadería y el beneficio de metales. En ellas trabajaban todo tipo de personas, las cuales vivían dentro de sus territorios, en poblados que contaban con iglesias, cárceles y varios talleres de artesanos. Sin la presencia constante de la tierra, como eje de producción y organización social, cualquier explotación metalífera hubiera sido imposible. Estas enormes posesiones, producto del derecho castellano, lo eran gracias al valor patrimonial y al prestigio que podía mantener una familia en la cúspide de la pirámide social, y también porque el vínculo con la tierra era una prerrogativa económica y cultural esencial para el funcionamiento de la territorialidad novohispana, tanto del señor como del campesino empotrado y depen- 
diente de la tierra. Si, por un lado, la minería constituía la actividad principal con la que se sustentaban las grandes cifras de las finanzas trasatlánticas, por el otro, es incuestionable que esta economía no hubiera podido funcionar sin la localización territorial de las relaciones económicas y sociales vinculadas con la tierra. Langue $(1999,305)$ señala que en las seis haciendas mencionadas, al menos vivía 69 por ciento de la población total del distrito, por lo general integrada por sirvientes, esclavos y operarios de las minas. Los indígenas foráneos (trabajadores libres) se empleaban mas bien en las faenas de las minas, llegaron a sumar casi 30 por ciento de los pobladores a lo largo de la segunda mitad del siglo XVIII. ${ }^{6}$ Los sirvientes representaban la verdadera fuerza de las haciendas; en Cedros había 182 familias, en Bonanza 113 y en La Gruñidora más de 140 (Langue 1999, 306). El tamaño de esta población indica un comportamiento estable y regular de los niveles demográficos y productivos de dichas haciendas, y de la función sociopolítica marginal de los grupos indígenas, quienes no habían logrado constituir pueblos de indios, por mantenerse dentro de la jurisdicción de ellas, como señala el padre Morfi en Viaje de indios y diario del Nuevo México, de 1779 (Langue 1999, 306). Sin embargo, la mayoría de los indígenas que vivían en las haciendas de beneficio, a pesar de ser considerados naborías (trabajadores libres), estaban sujetos a la autoridad del hacendado. Es significativo, en este sentido, que en 1550, en las ordenanzas de La Marcha, se le prohibiese al cuerpo administrativo y judicial de las ciudades que a los mineros se les asignaran indios, que llegaban de otras partes de la Nueva España. El sistema del repartimiento se abolió formalmente en 1632. Sin embargo, Von Humboldt $(1994,72)$ evidencia que, ese sistema nunca desapareció como praxis de explotación del trabajo indígena, por lo menos hasta la creación de las intendencias, en 1788. Durante la Colonia, la contratación de mano de obra indígena y, más en general, de "trabajadores libres”, parecía no respetar las directivas que, en varias ocasiones, emitiera el poder central para proteger a los indios de los abusos de los grandes poderes locales. Los gañanes o naborías a menudo se volvían dependientes del hacendado y, a pesar de que a la mayoría se le empleaba en las minas y recibía un salario por su trabajo, se tenían 
que sujetar al sistema de explotación corporativo de la hacienda. Hasta mediados del siglo XVIII, a las familias de estos obreros se les pagaba en especie; además, recibían un anticipo de su salario para ejercer un derecho exclusivo sobre su fuerza de trabajo, y para mantenerlos atados a la tierra. La utilización de incentivos a la producción, como el de la pepena, no determinaba algún tipo de autonomía de las familias indígenas y mestizas de la hacienda, pues los lazos de dependencia no se limitaban a una contratualidad de tipo laboral, sino hundían sus raíces en la esencia patronal y propietaria del sistema socioproductivo novohispano. Resulta entonces que el porcentaje de trabajadores que se podía definir como libre representaba sólo una parte minoritaria de la fuerza laboral empleada en las haciendas de beneficio de la Nueva Galicia y del norte de la Nueva España, por lo que se deduce que la economía agrominera, implementada por las familias de los propietarios en sus haciendas, no estaba determinada por el régimen salarial que hacía de unos cuantos grupos de individuos un cuerpo de trabajadores proletarizados. En Mazapil, la vigencia de este proceso parece estar demostrada por la ausencia de pueblos de indios en todo el periodo colonial, hecho que más tarde pudo favorecer la ocupación y el mantenimiento de las tierras por los latifundistas.

Por otra parte, los indios guachichiles, originarios de estos parajes, vivían en una condición de semiesclavitud, causada y perpetrada por las continuas luchas entre estos naturales y los colonizadores españoles desde mediados del siglo XVI (Bakewell 1997, 172). Es posible entonces hablar de una economía agrominera alrededor de la hacienda, porque la explotación de las minas y el beneficio de los metales, a pesar de que podían involucrar cierto número de trabajadores asalariados, nunca habían generado un tipo de desarrollo económico y social independiente del arraigo a la tierra. En la relación de la visita que Gaspar de la Fuente, oidor de la Audiencia de Nueva Galicia, hizo de las minas de Mazapil, entre 1608 y 1610, resulta que en las haciendas principales del lugar (Cedros y Bonanza) trabajaban por lo menos cien guachichiles (Pérez y García 2004, 99). Los metales obtenidos de las minas del real de Mazapil, debido a la escasez de agua (esencial para este tipo de operaciones), se mandaban a beneficiar a otros lugares. Sin embargo, la hacienda de Bonanza contaba con una planta de beneficio en donde se ocupaba una cuadrilla de guachichiles en el 
cuidado de las mulas, que servían de medio de trasporte para el mineral. Lo que falta por saber es si los 269 indios que trabajaban en el valle eran guachichiles "reducidos", o si había otros de origen diferente. De todos modos, es evidente que la población trabajadora, junto con los pocos esclavos negros ocupados en faenas domésticas (en la hacienda de Cedros eran diez) y los aún menos numerosos mestizos (tres en Cedros), dependía de la economía agrominera de Mazapil (Panico y Garibay 2010). De hecho, sólo una parte muy pequeña de la territorialidad novohispana (concebida como sentimiento de arraigo sociocultural y como sistema de explotación de un territorio) estaba influida por la actividad minera. Lo sostenido por Von Humboldt, que "los principales manantiales de la riqueza del reino de México no están en las minas sino en su agricultura” (1994, 237), no constituye una simple profecía, sino indica la importancia de la tierra como regulador de las relaciones económicas, políticas, sociales y culturales.

\section{Ejido y continuidad agrominera}

El estallido de la revolución, el despoblamiento paulatino de la región (muy superior al poblamiento de otras), el reparto agrario, la crisis de la hacienda como estructura sociopolítica y la consecuente crisis minera parecen caracterizar la segunda y la tercera década del siglo XX en Mazapil. La conjunción de estos factores frenó el proceso de cambio de la estructura agrominera del valle de los últimos 20 años del porfiriato. Como señalan Brading (1980, 15); Miller $(1991,72)$ y Tobler $(1990,168)$, la revolución no representó simplemente una revuelta campesina en contra de la injusticia, sino que se articuló como un proceso complejo que pudo haber tenido tintes muy diferentes de un lugar a otro. En Mazapil la transición revolucionaria no fue violenta, sino un evento trascendente, en la medida que significaba una trasformación del sistema de tenencia de la tierra y del arreglo sociodemográfico a la que dio origen. Sin embargo, como punto importante destaca que la estructura agrominera de la región se mantuvo intacta, aunque sus protagonistas y el tipo de organización social, que la sustentaron, cambiaron radicalmente. La economía familiar que se 
había empezado a asomar entre 1890 y 1910 , surgida de la presencia de la hacienda corporativista (localista) y la empresa capitalista (globalista), encontró continuidad en la estructura de la propiedad social representada por el ejido. En Mazapil, la revolución mexicana y las instituciones derivadas de ella sofocaron el cambio de una economía agrominera a una tecnoindustrial. El ejido garantizó la continuidad del vínculo histórico-ambiental, que había unido a la región y a sus pobladores con la tierra desde el comienzo de la aventura colonial. La estructura agrominera parece representar un elemento de continuidad histórica y cultural de apego a la tierra. El campesino, quien había estado en el centro del sistema de explotación agrícola por más de trescientos años, empezó a ser el protagonista de uno que lo protegía y cobijaba. El sistema paternalista de la hacienda novohispana fue sustituido por el del corporativismo partidista del sistema político posrevolucionario. Sin embargo, no se pudo detener el impulso modernista, iniciado con la llegada a Mazapil, de la gran industria extractiva (extranjera y de capital intensivo) durante los últimos 20 años del porfiriato. La función del reparto ejidal fue mantener viva, por lo que concierne a Mazapil, a una economía agrominera que empezó a debilitarse seriamente a partir del periodo de las reformas neoliberales, en la década de 1980. El territorio de Mazapil se había vuelto apetecible para un capitalismo en fermento y en expansión continua. Sin embargo, la continuidad agraria, garantizada por el ejido y fundamentada en la dependencia de la tierra y en la actividad ganadera, pronto se integró a una de tipo industrial, que servía de complemento en el marco de una economía agrocomunitaria de subsistencia. En Mazapil, las dificultades en la creación y estabilización de la organización ejidal impulsaron la necesidad, por parte de los campesinos, de buscar alternativas económicas en otros sectores de la producción. A las faenas del campo y de la ganadería se asociaba la recolección y el aprovechamiento de plantas silvestres (lechuguilla, candelilla, sotol y palma, entre otras), que se revendían dentro de los circuitos del mercado local (conectado con el desarrollo de Saltillo, de la Comarca Lagunera y con el crecimiento industrial de Monterrey), y también el trabajo en las empresas mineras que siguieron operando, sobre todo después de los años treinta (no obstante las nacionalizaciones del periodo cardenista). 
La situación descrita no determinó un cambio sustancial del orden agrominero, sino que lo favoreció. Las actividades agroforestales, vinculadas con productos como el aguardiente, el ixtle y al carbón vegetal tenían una función importante dentro de este tipo de organización, y creaban redes que conectaban las producciones del valle con compradores de origen diferente, así se ampliaron los espacios de intercambio. Por otro lado, la consolidación de las relaciones personales alrededor del ejido había provocado cierta unidad de la comunidad, por medio de su vínculo con la tierra. En Mazapil, al contrario de lo que habían profetizado los promotores de la Reforma Agraria y sus seguidores futuros (a excepción del sexenio cardenista), el trabajo de la tierra no constituía un complemento a otras formas de adquisición de los recursos económicos, sino que éstos terminaron convirtiéndose en un modo para integrar a la tierra. En Mazapil, las relaciones laborales asalariadas jamás fueron determinantes para mantener el equilibrio local durante casi todo el siglo XX. Esta suerte de economía local, que tendía a multiplicar el capital agrario (tierras y animales), indica que la actividad minera era sin duda muy importante, pero no dejaba de ser complementaria. La fuerza de los lazos sociales y de parentesco promovidos por la comunidad, son evidencia clara de esta mentalidad. Así que uno de los entrevistados durante el trabajo de campo, don Santiago, se "hizo de muchas chivitas". Los productos del trabajo minero asalariado se reinvertían en la ganadería de pequeña escala. El trabajo en las minas y en otras actividades, como la producción de carbón, obligaba al campesino a recurrir, con el pago de una suma pactada, a las redes familiares y sociales que le garantizaban no perder el capital que con mucha paciencia había ido juntando (un tío cuidaba las chivas de don Santiago por una compensación modesta cediendo "a medias" parte del capital).

La minería no era la única industria presente en la región, en Cedros, poblado próximo a Mazapil, las exigencias de la movilización bélica de la primera guerra mundial generaron una búsqueda intensa de recursos, para la fabricación de armas y, en general, para la producción de una economía de guerra. En 1906, la empresa estadounidense Continental Mexican Rubber se estableció en Torreón (enclave industrial importante del porfiriato), y de ahí empezó a expandir su control sobre el guayule, planta silvestre muy demandada por su alto 
rendimiento de látex (que se extraía de ella) a precio muy bajo. El desarrollo histórico de Cedros se puede considerar como un paradigma pequeño de la continuidad agrominera de esta parte del norte zacatecano. Durante el porfiriato, a la hacienda se le retiró el capital industrial extranjero, que amenaza con interrumpir la estructura socioproductiva local (Panico y Garibay 2011). Gracias al establecimiento del ejido, la revolución brindó continuidad al equilibrio agrominero, al que la inserción de las relaciones laborales asalariadas (y hasta sindicalizadas) no habían podido destruir. En consecuencia, cuando la empresa abandonó el valle, a los 150 obreros que trabajaban en ella se les ofrecieron tierras como compensación por la pérdida del empleo. Informantes actuales afirman, sin embargo, que la mayoría de estos obreros emigraron a centros vecinos (Torreón, Saltillo y Monterrey, entre otros) y que sus descendientes ahora se han acercado a reclamar la propiedad de estas tierras, debido a la bonanza minera actual. En Mazapil, la hacienda latifundista vio su ocaso definitivo con la llegada del capitalismo de empresa, cuya breve historia, a consecuencia de la revolución, no logró trasformar la región en un enclave industrial de mano de obra barata y asalariada.

\section{La incursión de la minería corporativa} y la ruptura del vínculo agrominero

A excepción de las huelgas y rebeliones del periodo revolucionario y posrevolucionario, los ejidos del actual municipio de Mazapil no cuentan con una tradición comunitaria de lucha. Los conflictos fueron consecuencia de coyunturas externas que repercutieron violentamente, pero sólo de forma transitoria, en el equilibrio de la región. Las pugnas mineras de la segunda y tercera décadas del siglo pasado se deben considerar como enfrentamientos entre una clase trabajadora proletarizada (casi desvinculada de la región y sus tierras) y las depresiones económicas periódicas, las cuales ya empezaban a manifestar su predisposición estructural ante la movilidad de las inversiones.

El ejido revolucionario, a pesar de sus limitaciones, funcionó como una institución protectora y fomentadora del régimen agrario, y permitió enfrentar los embates de un capitalismo que intentaba trasfor- 
mar zonas ricas en recursos estratégicos en enclaves de producción fabril (sobre todo actividades extractivas). La estructura agraria de la región resistió a la penetración de relaciones laborales típicamente industriales demostrando que la tradición histórica de Mazapil, a pesar de estar marcada por una minería intensa y prolongada, siempre conservó sus bases agrarias, aunque tuvo que ajustarlas a los tiempos. De eso resulta que no fueron tanto los lazos comunitarios internos al ejido los que favorecieron la continuidad de la estructura agrominera (hubo una petición de división del ejido de Cedros en 1978 por parte de algunos ranchos), sino elementos más trascendentes como la presencia de una institución comunitaria de gestión de los conflictos (el ejido), la vocación agraria y ganadera de los ejidatarios y el dinamismo escaso de un capitalismo industrial y financiero que, a pesar de la centralidad de la minería durante 500 años, nunca pudo condicionar el vínculo estrecho de los pobladores del valle con la tierra.

La llegada de la empresa Peñasquito, en 2006, junto con la desamortización sustancial, que desde 1992 permitió la nueva legislación agraria, están modificando radicalmente la complementariedad histórica entre agricultura, ganadería y minería en la región. Existe, por un lado, el horizonte localista arraigado en la tierra y el ejido y, por el otro, el globalismo representado por relaciones laborales móviles e inestables, típicas de un capital financiero disociado del territorio. Ahora bien, hasta 2007, año en que Goldcorp Inc. (la minera titular) empezó la construcción del megaproyecto, asociado con la extracción y procesamiento de los metales (oro, plata, zinc y plomo), la dimensión agrominera del valle de Mazapil no se había modificado sustancialmente por las grandes inversiones del capitalismo global. Esto quiere decir que las actividades industriales del pasado no habían logrado subvertir el patrón histórico regional, ya que las empresas no necesitaban un sistema de explotación masivo de los recursos (sociales y ambientales) autóctonos. Por el contrario, la nueva trasnacional no puede prescindir de una ocupación extensa y prolongada del territorio, ya que la extracción a tajo abierto, que se practica en este contexto, necesita una porción inmensa de tierras para el desarrollo de las diversas fases de su cadena productiva. Según comunicaciones oficiales de la empresa, se necesitan 18 años para explotar los recursos metalíferos del área. Sin embargo, los ejidatarios propietarios de 
las tierras incluidas en la zona minera las rentaron por 30 años, y algunos testimonios locales afirman que la compañía está adquiriendo más terrenos explotables, adyacentes o próximos al parque industrial actual. El sistema agrario del valle de Mazapil sigue girando alrededor de la figura institucional y social del ejido. Las tierras que hoy ocupan las instalaciones fabriles de la minera son propiedad de cuatro núcleos ejidales principales: Mazapil, Cerro Gordo, Cedros y El Vergel, todos pertenecientes al municipio de Mazapil. Como se ha visto, a pesar de la complejidad del proceso histórico mazapilense, la propiedad social de la tierra es la que ha caracterizado, de una forma tajante e incontrovertible, la vida de la región desde el comienzo de la Reforma Agraria. La estructura histórica que soporta al sistema actual de relaciones comunitarias constituye un claro obstáculo operativo para la moderna empresa de capitales y, al mismo tiempo, un atavismo cognitivo. Pese a la falta de lazos de identidad densos, el territorio de Mazapil mantiene todas las características de una sociedad campesina tradicional. A partir de sus comienzos, la aventura liberal va dejando en el camino la centralidad de la relación entre la tierra y la comunidad (Guzmán 2016). Sin embargo, la empresa capitalista tiene la necesidad apremiante de controlar la tierra para adueñarse de sus recursos, a los que proyecta fuera del espacio productivo local. En el caso de Mazapil, la racionalidad instrumental de la organización capitalista, representada por la minería, se apoya en estrategias que debilitan el funcionamiento comunitario del ejido, haciendo hincapié en estímulos que favorecen la adopción de una praxis de acción individual y autónoma por parte de los actores locales. La política de relaciones públicas de la compañía se ha dirigido a personalizar las negociaciones, lo que el cuadro normativo vigente le ha facilitado. El comunitarismo de la organización ejidal, no muy profundo en Mazapil por las circunstancias históricas mencionadas, había conseguido convertir la política agraria inicial, de comienzos del siglo XX, en un sistema de costumbres y de patrones de comportamiento reiterados. La Ley Agraria de principios de los años noventa agrietó este sistema, y les otorgó derechos plenos a los ejidatarios para disponer de la tierra, y ya no están obligados a trabajarla, como lo imponía los ordenamientos precedentes. En el contexto del rezago estructural del campo mexicano estas medidas han logrado, sólo en parte, generar la formación de una propiedad 
individual pequeña y mediana; en la mayor parte de los casos, han alentado a los campesinos a deshacerse de sus parcelas por necesidad, a cambio de compensaciones menguadas (De Ita 2003). A pesar de mantener formalmente el régimen de propiedad comunal, resulta evidente que las reformas a las legislaciones agraria, minera y de inversión extranjera han debilitado los núcleos ejidales favoreciendo las acciones de un mercado de tierras, que ya no las considera como un recurso para las comunidades, sino como un producto susceptible de capitalización. En Mazapil, la minera Peñasquito tuvo que construir una estrategia que le garantiza la disponibilidad de las tierras necesarias para sus actividades industriales. Por lo que concierne a la negociación de las tierras comunes de agostadero pertenecientes a los ejidos, sobre todo a Cedros, al principio la compañía les ofreció a sus representantes institucionales un pago por poco más de 50 mil pesos por ejidatario, por el arrendamiento durante 30 años del núcleo territorial sobre el cual se iba a instalar el proyecto. En una segunda negociación, la minera y el ejido Cedros celebraron otro contrato en el que éste concedía, por el mismo lapso, más de 5500 hectáreas de tierra (una cuarta parte de su territorio) en arrendamiento por poco más 40 millones de pesos. Además, la empresa había propuesto financiar una tortillería y una planta de procesamiento de carne, para abastecer de alimentos a sus empleados; otorgar becas escolares a los niños; favorecer la ocupación contratando a trabajadores locales y construir un centro de salud, para resolver la difícil situación sanitaria que obliga a los residentes a trasladarse a centros de atención distantes. Por otro lado, aprovechó el dilatado margen de acción que le permitían las normas en materia de legislación agraria, y negoció con individuos particulares, a los que ofreció un pago definitivo para adquirir directamente la propiedad de la tierra. En la localidad conocida como El Peñasquito, entre los ejidos de Cedros y Cerro Gordo, lugar en donde la compañía había detectado las vetas metalíferas más ricas, los pobladores originales fueron desplazados a colonias nuevas (edificadas por la minera). También se les ofreció una compensación considerable en efectivo, y se les compraron los animales con los que se sostenía su pequeña actividad ganadera. El paisaje de estos barrios de creación reciente muestra un contraste llamativo entre la forma en la que la empresa moderna concibe un sistema de asentamiento hu- 
mano, y la respuesta que la cultura campesina genera para reproducir sus espacios de vida dentro de la nueva organización habitacional. Quizá este sea el ejemplo más emblemático de las trasformaciones que se están produciendo en el equilibrio agrominero tradicional de la región. Hay dos factores que terminaron por debilitar las relaciones comunitarias en el valle, uno estructural interno, la prolongada estructura agrominera, junto con otro coyuntural externo, representado por la debilitación legislativa de principios de los años noventa. Por otro lado, este largo tejido temporal de matriz agrominera constituye el horizonte que otrora determinara la posibilidad de una estructura comunitaria en Mazapil, dentro de una dialéctica histórica que marca la genealogía peculiar de este territorio, y la respuesta actual que producen sus habitantes ante la llegada de la nueva minería corporativa.

\section{Conclusiones}

Es muy importante subrayar que las tres divisiones propuestas no derivan de la idea de que el cambio histórico en Mazapil se produce sólo en correspondencia con los hitos metabólicos mencionados al principio. Éstos sólo sirven para subrayar la importancia de las trasformaciones de los patrones energéticos materiales dentro de las relaciones socioambientales. La historia representa un proceso ininterrumpido de cambio, por eso el periodo entre el establecimiento de los reales mineros, a mediados del siglo XVI, y la llegada de las grandes empresas mineras, a principios del siglo XX en México, no se puede considerar como un bloque homogéneo. Lo que sí es posible plantear es que, durante ese tiempo, el metabolismo sobre el que primero se sostenía el mundo novohispano, y después el México del primer periodo independiente, no había sufrido modificaciones importantes.

En el caso del Virreinato, el hito metabólico correspondiente es el que separa la territorialidad indígena de la que instituye el conquistador español. En ese momento, el metabolismo colonial del valle aún estaba basado en la tierra. La minería era una actividad sustancial, que seguía dependiendo de la producción energética garantizada por la agricultura y la ganadería. Durante el porfiriato, con la llegada de 
un capitalismo en búsqueda de espacios de inversión, se asiste a un segundo salto metabólico que se ve atemperado (aunque no vencido) por los acontecimientos revolucionarios y la puesta en marcha de la Reforma Agraria. En la actualidad se observa una descomposición rápida de los equilibrios metabólicos anteriores ocasionada por una minería capaz de movilizar y trasformar cantidades enormes de materia. Los recursos locales se ven absorbidos dentro de un torbellino energético que los agota; la tierra, el agua y el trabajo representan el paradigma de esta explotación salvaje. La minería moderna abre una ventana sobre las formidables masas de energía necesarias para alimentar la maquinaria de la producción ampliada. El gran dispendio energético que hoy requiere el proceso productivo hegemónico, para plasmar un medio conforme a sus exigencias, es increíblemente mayor al de los sistemas histórico-metabólicos anteriores. La minería, y en particular el caso de Mazapil, permiten refrendar la vigencia y la importancia del análisis historiográfico-ambiental, sobre todo en su sentido ético. Pese a que el metabolismo de la sociedad agrominera colonial en nada es comparable con el actual, es evidente que, hace casi 500 años la minería representaba una actividad revolucionaria, en términos de movilización y consumo de la energía. No se debe olvidar que la plata americana movía los destinos del mundo entero, y nutría el comercio que la metrópoli europea sostenía con tierras orientales. Durante la primera fase de expansión del capitalismo, que en México se manifestó sobre todo hacia finales del siglo XIX, este gran aparato de sustento productivo del mundo se hizo gigantesco, pues la reproducción del capital no sólo necesitaba ámbitos de inversión nuevos, sino también un acotamiento sustancial del tiempo, esto último generó un cambio cualitativo sin precedentes en la percepción de la historia.

Hoy los patrones metabólicos, inaugurados por la expansión de la minería a cielo abierto, se han hecho tan grandes que no hay forma de que alguna actividad social, vinculada con el aprovechamiento del medio, pueda subsistir junto a ella. En todas las épocas la minería ha sido energéticamente desestabilizante y promotora de cambios históricos importantes; Mazapil es un ejemplo claro de ello. Es por eso que su estudio puede representar un ámbito privilegiado dentro del campo de la historia ambiental; incluso se podría decir que la minería puede constituir uno de los fundamentos más sólidos para la histo- 
ria ambiental en términos teóricos y metodológicos. Epistemológicamente, una historia ambiental no puede prescindir de sus elementos estructurales y, por ende, tampoco verse como una historiografía separada de las tradiciones más consolidadas de la historia social y la geohistoria (Flórez 2002; Meléndez 2002). El meollo del asunto no estriba entonces en una diferenciación metodológica estricta (como lo propuso Braudel), entre una historia "larga", una "mediana" y una "corta”, sino en cómo se vienen repitiendo las instancias históricas del pasado, en el momento en que el historiador decide fijar el punto de partida de sus pesquisas. La historia de la minería se presenta como un campo de conocimiento esencial, pues ofrece el terreno documental para fundamentar la dialéctica borrosa entre "sociedad" y "naturaleza", que de ningún modo se puede resolver dentro de una definición filosófica estricta. ${ }^{7}$

A manera de resumen, los hitos metabólicos en Mazapil dialogan con la propuesta braudeliana: el primero inaugura un periodo histórico basado en un régimen agrominero, integrado dentro de una economía del tipo "valle agrícola-monte minero", mientras que el último cierra esta continuidad debido a que la empresa corporativa se instala en el corazón del valle, y rompe la integración mencionada. El segundo hito hizo tambalear la persistencia agrominera, aunque no pudo romperla debido a dos factores: la minería seguía siendo una actividad de "monte", y la Reforma Agraria le brindó continuidad al sistema, y lo hizo transitar hacia el corporativismo político de la revolución institucionalizada del siglo XX.

\section{Archivos}

Archivo Agrario del Estado de Zacatecas: dedos 001-212; Mazapil agrario dos 001-317; Mazapilex duodos 001-358.

Archivo Histórico del Municipio de Mazapil: aún no catalogado.

7 Para mayor información sobre este tema, véase Babbington (2009) y González de Molina y Toledo (2011). 


\section{Bibliografía}

Acevedo Tarazona, Álvaro y Sebastián Martínez Botero. 2005. Temas, problemas y relatos para la historia ambiental. Anuario de Historia Regional y de las Fronteras X (1): 13-39.

Babbington, Anthony. 2009. Contesting environmental transformation, political ecologies and environmentalisms in Latin America and the Caribbean. Latin American Research Review 44: 177-186.

Bakewell, Peter. 1997. Minería y sociedad en el México colonial. Zacatecas (15461700). México: Fondo de Cultura Económica (FCE).

Boni, Andrés, Claudio Garibay, Francesco Panico y Pedro Urquijo. 2014. Corporación minera, colusión gubernamental y desposesión campesina. El caso de Goldcorp Inc. en Mazapil, Zacatecas. Desacatos 44: 113-142.

Boni Noguez, Andrew Félix. 2010. Transformaciones históricas del paisaje minero de Mazapil, Zacatecas. Tesis de maestría en geografía, Morelia: Centro de Investigaciones en Geografía Ambiental, Universidad Nacional Autónoma de México.

Brading, David. 1980. Caudillo and Peasant in the Mexican revolution. Cambridge: Cambridge University Press.

Braudel, Fernand. 2001. El Mediterráneo y el mundo mediterráneo en la época de Felipe II. 2 volúmenes. México: FCE.

Burke, Peter. 1992. Una rivoluzione storiografica. La scuola delle Annales, 19291989. Bari: Edizioni Laterza.

De Ita, Ana. 2003. Impactos del Procede en los conflictos agrarios y la concentración de la tierra. México: Centro de Estudio para el Cambio en el Campo Mexicano. 
Descola, Philippe y Gísli Pálsson (coordinadores). 2001. Naturaleza y sociedad:perspectivas antropológicas. México: Siglo XXI.

Escobar, Arturo. 2006. Difference en conflict in the struggle over natural resources: a political ecology framework. Development, Society of International Development 49: 6-13.

Flórez, Alberto. 2002. La historia ambiental frente a las ciencias sociales. En Repensando la naturaleza: encuentros y desencuentros disciplinarios en torno a lo ambiental, compilado por Germán Palacio y Astrid Ulloa, 113122. Colombia: Universidad Nacional de Colombia-Sede Leticia, Instituto Amazónico de Investigaciones, Instituto Colombiano de Antropología e Historia.

García, Manuel Andrés. 2006. Historia y medio ambiente: el sentido de la historia dentro del análisis ambiental por dimensiones. Gestión y Ambiente 9 (3): 91-98.

Georgescu-Roegen, Nicholas. 1996. La ley de la entropía y el proceso económico. Madrid: Fundación Argentaria.

González de Molina, Manuel y Víctor Toledo. 2011. Metabolismos, naturaleza e historia. Una teoría de las transformaciones socioecológicas. Barcelona: Icaria.

Guzmán López, Federico. 2016. Economía política del despojo territorial. Megaminería a cielo abierto en Zacatecas bajo el capital global 1982-2104. Tesis de doctorado en estudios del desarrollo. Zacatecas: Universidad Autónoma de Zacatecas.

Langue, Frédérique. 1999. Lo señores de Zacatecas. Una aristocracia minera del siglo XVIII novohispano. México: FCE.

Latour, Bruno. 2007. Nunca fuimos modernos. Ensayo de antropología simétrica. Buenos Aires: Siglo XXI. 
Leff, Enrique. 2005. Construindo a história ambiental de América Latina. Esboços 13: 11-30.

Martínez Alier, Juan. 1995. Curso de economía ecológica. México: Programa de las Naciones Unidas para el Medio Ambiente.

Meadows, Dennis, Jorgen Randers, Donella Meadows y William Behrens III. 1972. Los límites del crecimiento. México: FCE.

Meléndez, Silvia. 2002. La historia ambiental: aportes interdisciplinarios y balance crítico desde América Latina. Cuadernos Digitales 19 (7): 1-48.

Miller, Simon. 1991. Land and labour in Mexican rural insurrections. Bulletin of Latin American Research 10: 55-91.

Panico, Francesco y Claudio Garibay Orozco. 2011. Minería y territorio: una mirada al conflicto desde Mazapil, Zacatecas (México). Dimensión Antropológica 52: 123-153.

Panico, Francesco y Claudio Garibay Orozco. 2010. Mazapil, Zacatecas, México: un ejemplo de estructura agroganadera colonial (1568-1810). Fronteras de la Historia 15 (1): 61-84.

Pérez Zevallos, Juan Manuel y Valentina García Martínez. 2004. El real y minas de San Gregorio de Mazapil 1568-1700. México: Instituto Zacatecano de Cultura "Ramón López Velarde".

Prigogine, Ilya. 2004. Las leyes del caos. Barcelona: Editorial Crítica.

Saba, Filippo Andrea. 2000. Dal paesaggio all'impresa. La storia ambientale fra strumento enciclopedico e scienza olistica. Florencia: European University Institute.

Sieferle, Rolf Peter. 1993. Perspectivas de una investigación medioambiental histórica. Debats 45: 55-80. 
Tobler, Hans Werner. 1990. Los campesinos y la formación del estado revolucionario, 1910-1940. En Revuelta, rebelión y revolución: la lucha rural en México del siglo XVI al siglo XX, compilado por Friedrich Katz, 431456, tomo 2. México: Ediciones Era.

Toledo, Víctor. 2013. El metabolismo social: una nueva teoría socioecológica. Relaciones: Estudios Históricos y Sociales 136: 41-71.

Toledo, Víctor y Manuel González de Molina. 2007. El metabolismo social: las relaciones entre la sociedad y la naturaleza. En El paradigma ecológico de las ciencias sociales, coordinado por F. Garrido Peña, M. González de Molina, J. L. Serrano Moreno y J. L. Solana Ruiz, 85112. Barcelona: Icaria.

Von Humboldt, Alexander. 1994. Ensayo político sobre el reino de la Nueva España. México: Editorial Porrúa.

Worster, Donald. 2008. Transformaciones de la tierra. Montevideo: Coscoroba Ediciones. 